\title{
Orientation system of solar panels based on a robot manipulator
}

\author{
Ahmed CHAÏB $^{1}$, Dalila ACHELI ${ }^{1}$, Mohamed KESRAOUI ${ }^{1}$ \\ ${ }^{1}$ Applied Control Laboratory, University of Boumerdes 35000 Algeria \\ Phone number: 00213661548116, Fax number: 0021321215729, E-mail: chaib_ah@yahoo.fr, dacheli2000@yahoo.fr, \\ mkesraoui@umbb.dz
}

\begin{abstract}
Solar energy is one of the most interesting renewable energies, as it is an inexhaustible natural accumulation. The electrical energy generated depends on the performance of photovoltaic panels that is based on the direction of sunlight.

The position of the sun changes during the day, even during the year, which imposes a system of automatic orientation of solar panels for this purpose, several devices have been proposed and marketed.

In our article, we focus on the adaptation of a robot manipulator for orientation and positioning of solar panels, applying for the control system, the model of the robot controller.

First, we present the robotic system, which is a well-mastered, and his order was the subject of several studies and applications, and the model of the robot used for controlling the system.

Finally, we give the simulation results in two modes: Mode fixed facing south with an inclination of $45^{\circ}$ and the robot tracking mode following the elevation and azimuth movements with two decoupled movement. The results found show a gain in terms of solar energy collected measured about $51 \%$.
\end{abstract}

\section{Key words}

solar panel, solar radiation, Tracking System, Robot manipulator control model.

\section{Introduction}

The electric power produced by a solar photovoltaic system depends on the intensity of light output depending on the position of the sun varies throughout the day.

To collect the maximum energy, we use tracking devices. The solar tracking system must be adjusted so that the photovoltaic panels are always perpendicular to solar radiation. The solar tracking systems to a single axis are less expensive and their control is easy to implement, but, their efficiency is lower than that of tracking systems Biaxial [1].
The latter requires an appropriate control of the two movements are decoupled and used in thermal concentrating heliostats for guiding [2] and for photovoltaics to increase their efficiency which can reach values of $30 \%$ compared to systems stationary [3].

\section{Solar Potential in ALGERIA [5]}

According to its geographical situation, Algeria holds one of the highest solar reservoirs in the world. The illumination time over the quasi-totality of the national territory exceeds 2000 hours annually and may reach 3900 hours (high plains and Sahara). The daily obtained energy on a horizontal surface of $1 \mathrm{~m}^{2}$ is of $5 \mathrm{kWh}$ over the major part of the national territory, or about 1700 $\mathrm{kWh} / \mathrm{m}^{2}$ / year for the North and $2650 \mathrm{kWh} / \mathrm{m}^{2} /$ year for the South of the country. The solar deposit exceeds the 5 billion GWh and the solar potential is summarized in Table 1 [5]:

Table 1: Solar Potential in Algeria [5]

\begin{tabular}{|c|c|c|c|}
\hline Areas & $\begin{array}{c}\text { Coastal } \\
\text { Area } \\
\text { (North) }\end{array}$ & $\begin{array}{c}\text { High } \\
\text { Plateau } \\
\text { (Centre) }\end{array}$ & $\begin{array}{c}\text { The } \\
\text { Sahara } \\
\text { (South) }\end{array}$ \\
\hline Surface \% & 4 & 10 & 86 \\
\hline $\begin{array}{c}\text { Average duration of } \\
\text { Sunshine (hours / } \\
\text { annum) }\end{array}$ & 2650 & 3000 & 3500 \\
\hline $\begin{array}{c}\text { Received Average } \\
\text { Energy (kWh / m²/ } \\
\text { annum) }\end{array}$ & 1700 & 1900 & 2650 \\
\hline
\end{tabular}


The monthly average daily irradiation per square meter $\left(\mathrm{kwh} / \mathrm{m}^{2} /\right.$ day), for the months of December (winter) and July (summer) are respectively indicated in the solar charts of Fig. 1 and Fig. 2 [5].

As shown in Fig.1, during July the majority of the country is under daily irradiations greater than $7.5 \mathrm{kWh} / \mathrm{m}^{2} /$ day, and in some regions in the extreme south east (Province of ILLIZI, $1900 \mathrm{~km}$ from Algiers) this can reach 9 $\mathrm{kWh} / \mathrm{m}^{2} /$ day. During the coolest month of December, Fig. 2, the big south of Algeria still receive solar irradiation between 6 and $8.5 \mathrm{kWh} / \mathrm{m}^{2} /$ day especially in the south west region.

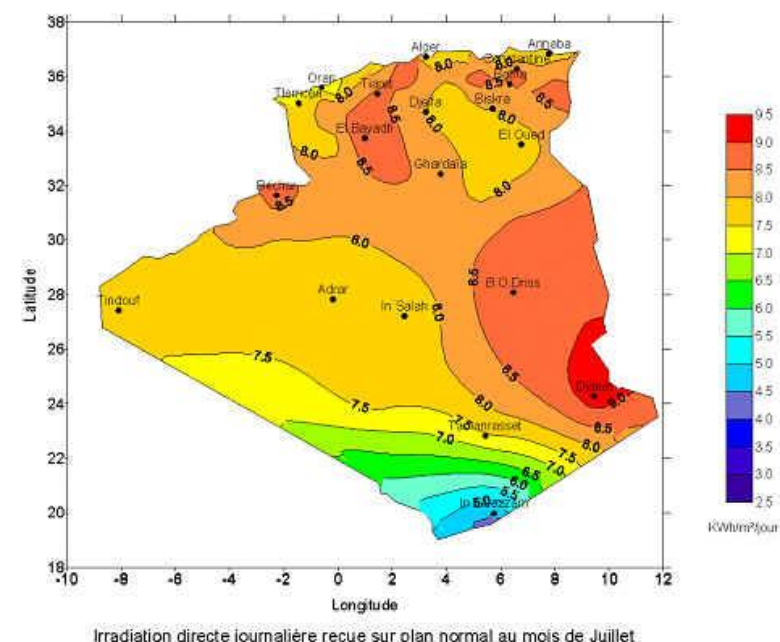

Fig. 1. Daily Solar Irradiation for July (summer) [5]

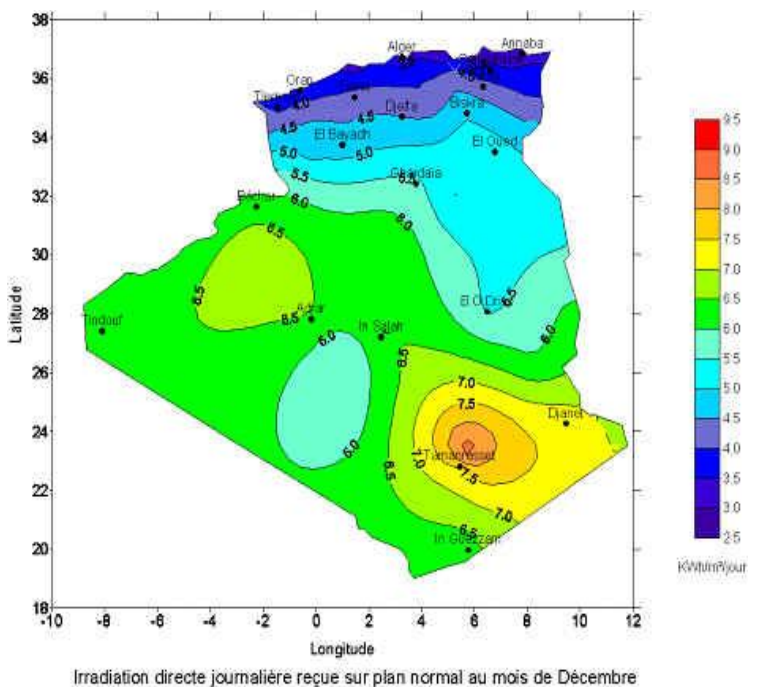

Fig. 2. Daily solar Irradiation for December (winter) [5]

\section{3 - Modeling the robot used}

In this work, we used a robot arm (manipulator with two degrees of freedom), the orientation of the solar panel to track the sun.

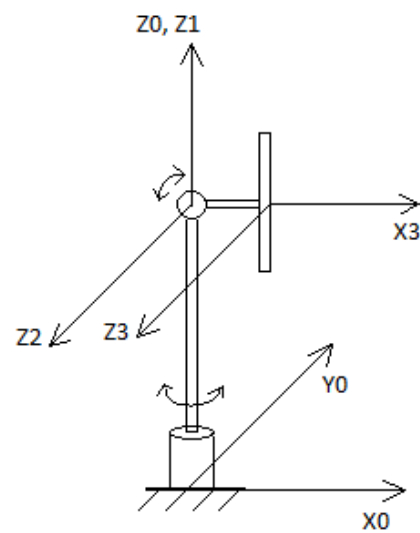

Fig. 3. Robot manipulator with two axes

The purpose of the order is to match the $\mathrm{X} 3$ axis with solar radiation

The homogeneous transformation matrix [4] of base reference to the reference connected to the solar panel:

${ }^{0} \mathrm{~T}_{3}=\left[\begin{array}{cccc}C 1 . C 2 & -C 1 . S 2 & S 1 & d 2 . C 1 . C 2 \\ S 1 . C 2 & -S 1 . S 2 & -C 1 & d 2 . C 2 \\ S 2 & C 2 & 0 & d 2 . S 2+r 1 \\ 0 & 0 & 0 & 1\end{array}\right]$

Where: $\mathrm{Ci}=\operatorname{Cos}\left(\Theta_{\mathrm{i}}\right)$ et $\operatorname{Si}=\operatorname{Sin}\left(\Theta_{\mathrm{i}}\right)$

The orientation of the $\mathrm{X} 3$ axis in the coordinate $\mathrm{R} 0$ is given by the column vector ${ }^{0} \mathrm{~S}_{3}$ following:

$$
{ }^{0} \mathrm{~S}_{3}=\left[\begin{array}{lll}
\mathrm{C} 1 . \mathrm{C} 2 & \mathrm{~S} 1 . \mathrm{C} 2 & \mathrm{~S} 2
\end{array}\right]^{\mathrm{T}}
$$

Where: $\Theta_{1}$ is the angle of rotation of the first axis of a robot, and $\mathrm{\Theta}_{2}$ is the angle of rotation of the second axis of the robot, and they represent the parameters of the robot controller.

If we consider the $\mathrm{X} 3$ axis, must follow the sun in two directions, vertical and horizontal 


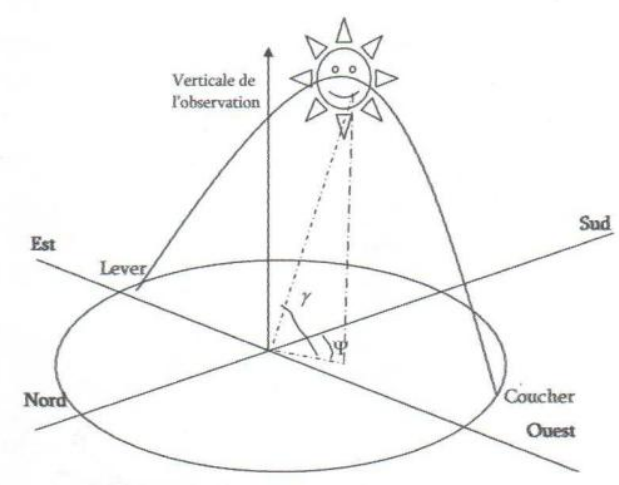

Fig. 4. Contact angle of sun

The orientation of the sun along the axes $\mathrm{X} 0, \mathrm{Y} 0$ and $\mathrm{Z} 0$ represented by the South West and the vertical is respectively:

Along the axis X0: $\operatorname{Cos}(\gamma) \cdot \operatorname{Cos}(\varphi)$

Along the axis Y0: $\operatorname{Cos}(\gamma) \cdot \operatorname{Sin}(\varphi)$

Along the axis Z0: $\operatorname{Sin}(\gamma)$

In terms of comparing expressions 2 and 3, we can conclude:

$\Theta_{1}=\gamma$ and $\Theta_{2}=\varphi$

\section{Simulations results and discussion}

To evaluate the effectiveness of the robot manipulator, a comparative study of solar energy collected, between it and a fixed system facing south and tilted 45 degrees to the horizontal was performed.

The result of simulation, are shown in Fig. 5, Fig. 6, Fig. 7 and Fig. 8.

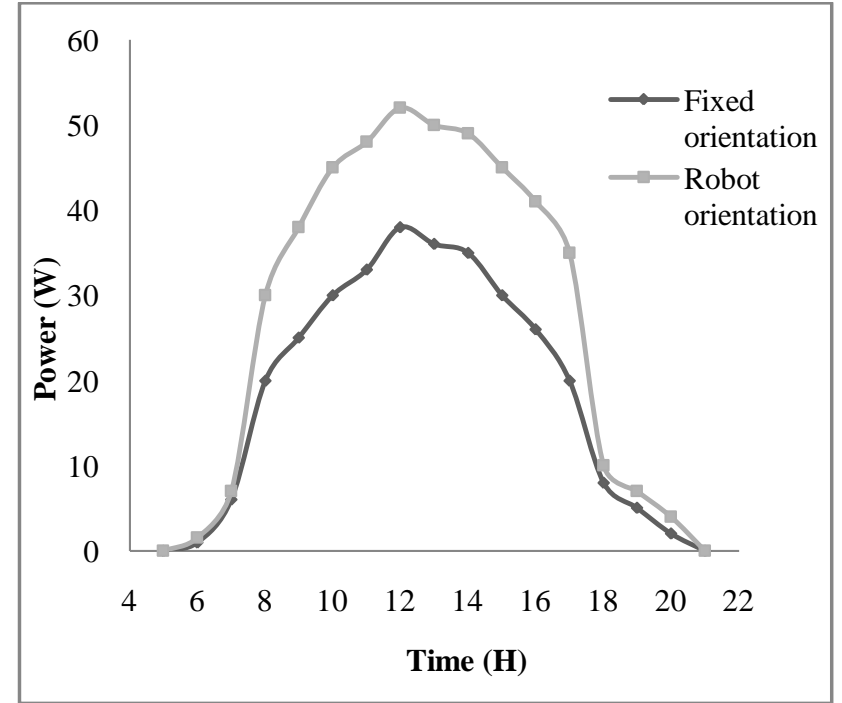

Fig. 5: The power variation of a photovoltaic module (summer)

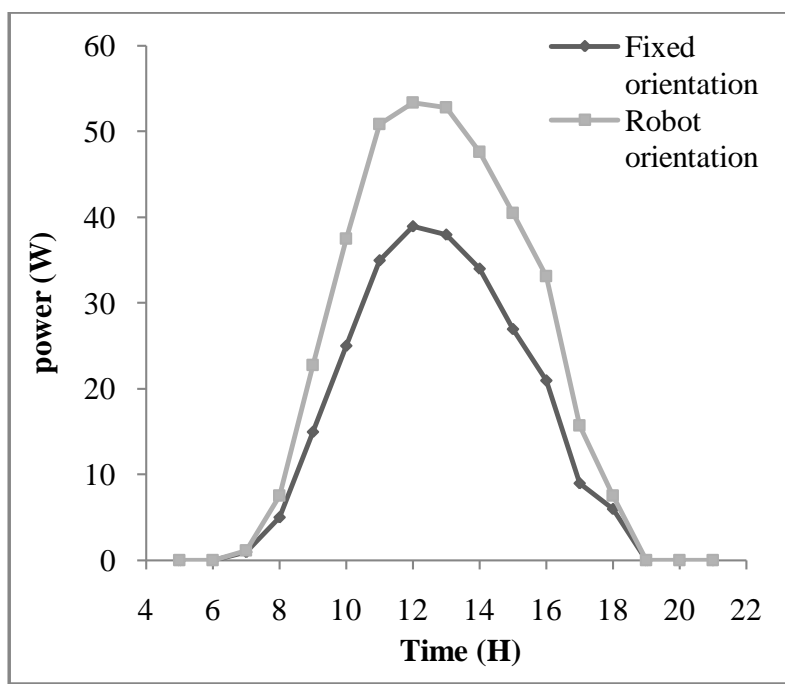

Fig. 6: The power variation of a photovoltaic module (spring)

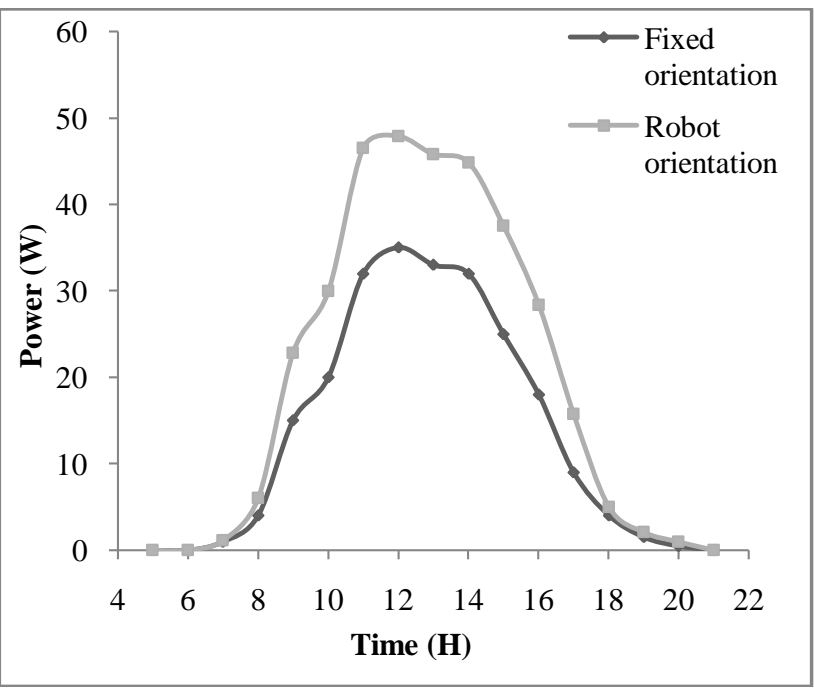

Fig. 7: The power variation of a photovoltaic module (autumn)

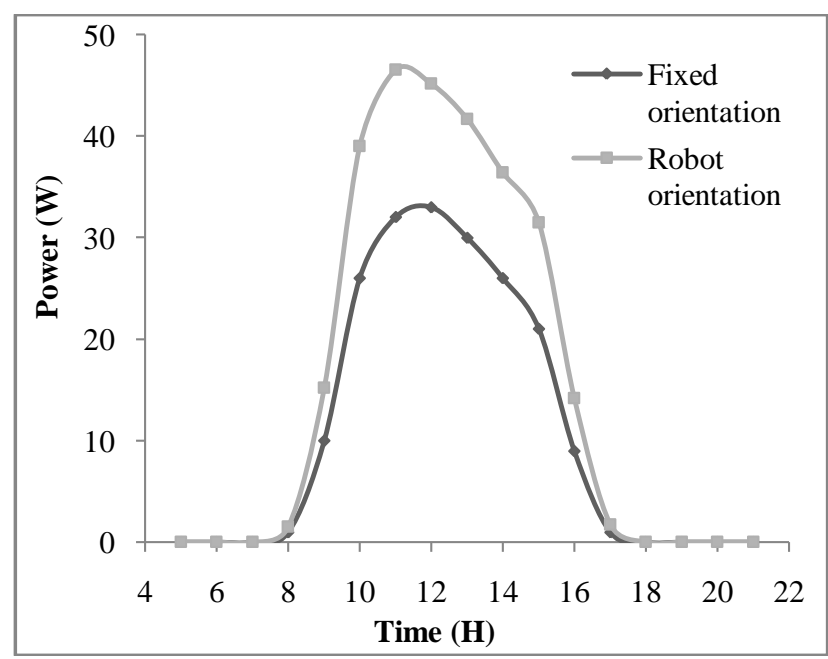

Fig. 8: The power variation of a photovoltaic module (winter) 
The power collected through the solar panel orientation using the robot manipulator is very important during the day, we notice that it deviates from that collected by the fixed system.

The power drawn is collected by the two systems are similar in early and late in the day.

The maximum energy noticed when simulation is obtained between $11 \mathrm{~h}$ and $14 \mathrm{~h}$.

\section{Conclusion}

In this work, we applied a solar tracking system based on a robot arm with two degrees of freedom, where emphasis was placed on the mastery of their mechanical robots and primarily of their control.

Now we know how to make robots that can move a powerful solar panel with high precision and low power, which allows possible energy autonomy of the system.

We then used the model of the robot controller in order to integrate them into the automatic control of sun tracking.

The simulation system has allowed us to see the possibility of combining the robot arm to solar energy.

The simulation results have mounted a very significant energy savings of about $50 \%$ compared to the fixed system, even for some guidance.

The prospects of this work are the implementation of the system in reality in order to realize the importance and the gain in terms of energy that can make this achievement.

\section{References}

[1] S. Abdallah and S. Nijmeh, 'Design, Construction and Operation of One Axis Sun Tracking System with PLC Control', Jordan Journal Applied Science University, 2002, pp. $45-53$.

[2] Abdul-Jabbar N. Khalifa and Al-Mutawalli S. Salman, 'Effect of Two-Axis Sun-Tracking on the Performance of Compound Parabolic Concentrators', Energy Conversion and Management, 1998, Vol. 39, $\mathrm{N}^{\circ} 10$, pp. 1073 - 1079.

[3] J. Bione, O.C. Vilela and N. Fraidenraich, 'Comparison of the Performance of PV Water Pumping Systems Driven by Fixed, Tracking and V-Trough Generators', Solar Energy, 2004, Vol 76, N³, pp. $703-711$.

[4] E. Dombre, W. Khalil, Modélisation et commande des robots, Editions HERMES, Paris 1988.

[5] Algerian ministry of energy and mining Web page: http://www.mem-algeria.org 